\title{
Micro-fluidic applications of telephone cord delamination blisters
}

Alex A. Volinsky, Patrick Waters, Gregory Wright

University of South Florida, Dept. of Mechanical Engineering, Tampa FL 33620 USA

Volinsky@eng.usf.edu; http://www.eng.usf.edu/ volinsky

\begin{abstract}
Argon pressure significantly affects the residual stress in sputter deposited thin films and coatings. In case of $\mathrm{W}$ thin films, high residual stresses on the order of 1-2 GPa are quite common. With the rest of sputtering parameters being equal, argon pressure determines the sign and the value of residual stress.

When the amount of stored elastic energy in the film due to the residual stress exceeds the interfacial toughness, fracture normally occurs. Telephone cord buckling delamination blisters are commonly observed in compressed thin films. These mechanically active features form by a loss of adhesion between the film and the substrate due to residual stress relief, and exhibit directional growth under certain conditions. This paper considers telephone cord delamination channels for micro-fluidics applications, as this could to be a valuable, reliable, and inexpensive method of forming open channels.
\end{abstract}

\section{INTRODUCTION}

Microfluidics as a field has been growing with the new advances in nanotechnology [1]. This field has been estimated to grow at a near exponential rate in the decades to come. This relatively new technology has different possible applications, including drug delivery. Pharmacological agents could be successfully delivered directly to the wound sites [2]. The technology relies on the ability to transfer fluids through micro-channels. These channels are commonly etched in silicon by means of standard methods of lithography, although there are multiple steps involved [3], and the whole process is cumbersome, expensive, and labor intensive.

Here, we present an alternative in the form of thin film delamination blisters forming open micro-channels. Telephone cord deamination morphology is commonly observed as a result of the thin film residual compressive stress relief by interfacial debonding (Figure $1 \mathrm{a}$ ). Here, biaxial film stress is partially relieved by film buckling in the direction perpendicular to the telephone cord propagation, and by "secondary" blister buckling in the direction of telephone cord propagation, which results in the sinusoidal fracture patterns $[4,5]$. Detailed dynamics of real time telephone cord blister propagation can be observed online [6]. Normally telephone cord blisters "run out of steam" and stop once the interfacial toughness exceeds the strain energy release rate. It is possible to make blisters propagate further by either putting mechanical energy into the system [5], or by introducing liquids at the crack tip [7]. Liquids can also provide the mechanical energy (through surface tension and capillary forces) needed to continue blisters propagation, as well as reduce the film interfacial toughness. We attribute this to environmentally-assisted cracking causing thin film delamination, similar to a commonly known example of degradation and fading of vintage mirrors. Studies of second surface solar mirrors have shown signs of delamination, and the effect of moisture was ruled out as a dominant failure mechanism [8]. 
Tests have been formulated that demonstrate fluid introduction as a method of propagating delamination blisters. These blisters continue to propagate until the fluid has been removed, or until the delamination reaches the end of the sample [7]. All samples contained a $1 \mu \mathrm{m}$ thick $\mathrm{W}$ superlayer, deposited on either thin magnetic layers, or a 40 $\mathrm{nm} \mathrm{Cu}$ films on $\mathrm{Si}$ substrates with a thermally grown $\mathrm{SiO}_{2}$ layer. Originally, $\mathrm{W}$ superlayer was used for thin film adhesion measurements [9].

\section{FLUID TRANSPORT IN DELAMINATING BLISTERS}

Figure 1 a shows two $50 \mu \mathrm{m}$ wide straight channels, which coalesce by forming a telephone cord delamination blister, resulting in a single $50 \mu \mathrm{m}$ wide channel.

Profilometer scan in Figure $1 \mathrm{~b}$ reflects the blister buckling geometry. This demonstrates a possibility of a fluid mixing device employing thin film buckling channels. In this particular case, the double-to-single channel transition occurred naturally, although lithographic techniques have been demonstrated to control the buckling geometry [10].
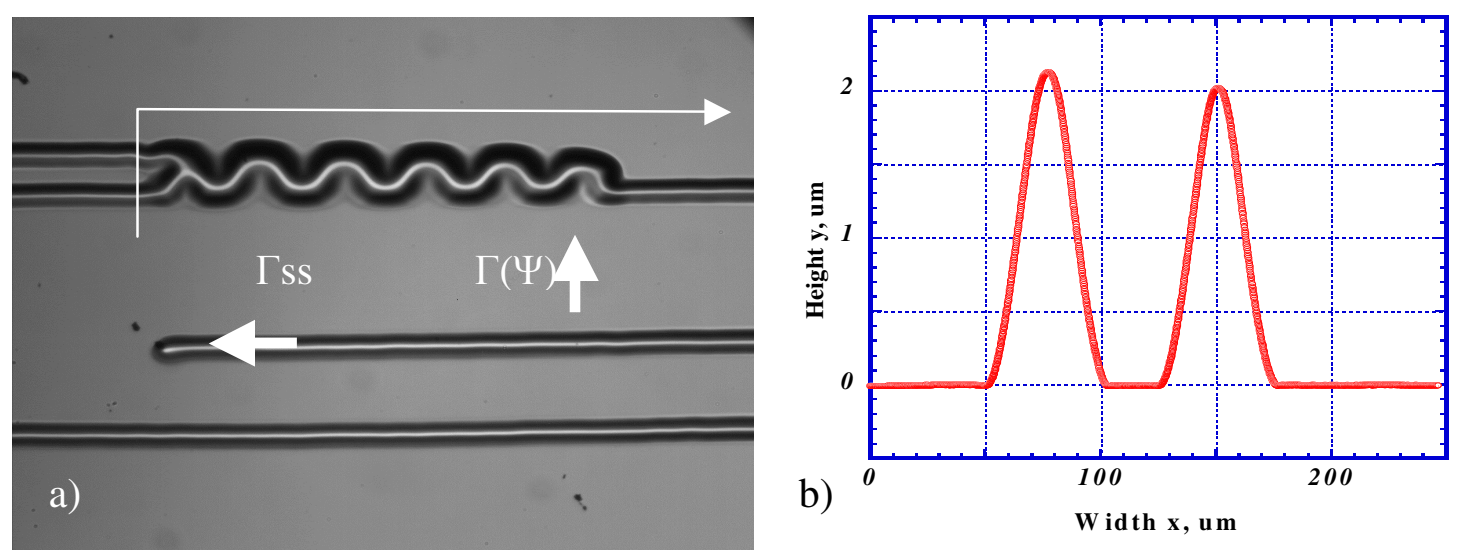

Figure 1. a) Optical micrograph of two straight buckled channels coalescing into one though a telephone cord delamination, and b) corresponding height profile.

It was also shown that introduction of water causes blisters to grow by means of some sort of environmentally-assisted fracture process [7]. Figure 2 shows two snapshots, taken 3 minutes apart, showing water-induced blister propagation. The evidence of fluid transport is presented in Figure 3. Here, buckling delamination propagated from the right to the left, and upon reaching the far left side of the sample, water was moving down the edge of the Si wafer. This demonstrates a potential of the fluid transport with blister propagation. In this case, water is transported with the advance of the crack tip at about $10 \mu \mathrm{m} /$ minute, although higher propagation rates, up to several microns per second were observed in other samples. It has been previously shown that interfacial cracks in thin films act as a vacuum cleaner, collecting contaminants from the atmosphere, thus reducing the energy of the newly-formed fracture surfaces [11, 12]. In this case, crack is acting like a pump, transporting fluid along with the blister propagation, and water droplets are seen on the Si substrate in Figure 3.

Other fluids can be transported through the microchannels as well. The experimental results have been duplicated with various oils. Straight weight 40 , machining oil, and 3 in 1 oil were all used on pieces of the same sample, and resulted in 
different blister propagation rates. The crack propagation rate depends on the level of compressive residual stress in the film, its adhesion, and the liquid properties. Crack propagation rates on the order of several microns per second have been achieved with water in the highly stressed samples.

For the same level of residual stress the delamination rate varies greatly depending on the fluid. Out of all the oils tested, the 3 in 1 oil caused the most rapid blistering, moving at $3 \mu \mathrm{m} /$ minute. The capillary force depends on the fluid surface tension and viscosity. When a more viscous fluid was introduced the blister propagated at a much slower rate. In this instance the surface tension would have been increased, but the fluid tendency to wet becomes a restrictive factor. Tests were repeated with water heated to $40^{\circ} \mathrm{C}$, which did not have much of en effect, as the blister propagation occurred at approximately the same rate as at room temperature.

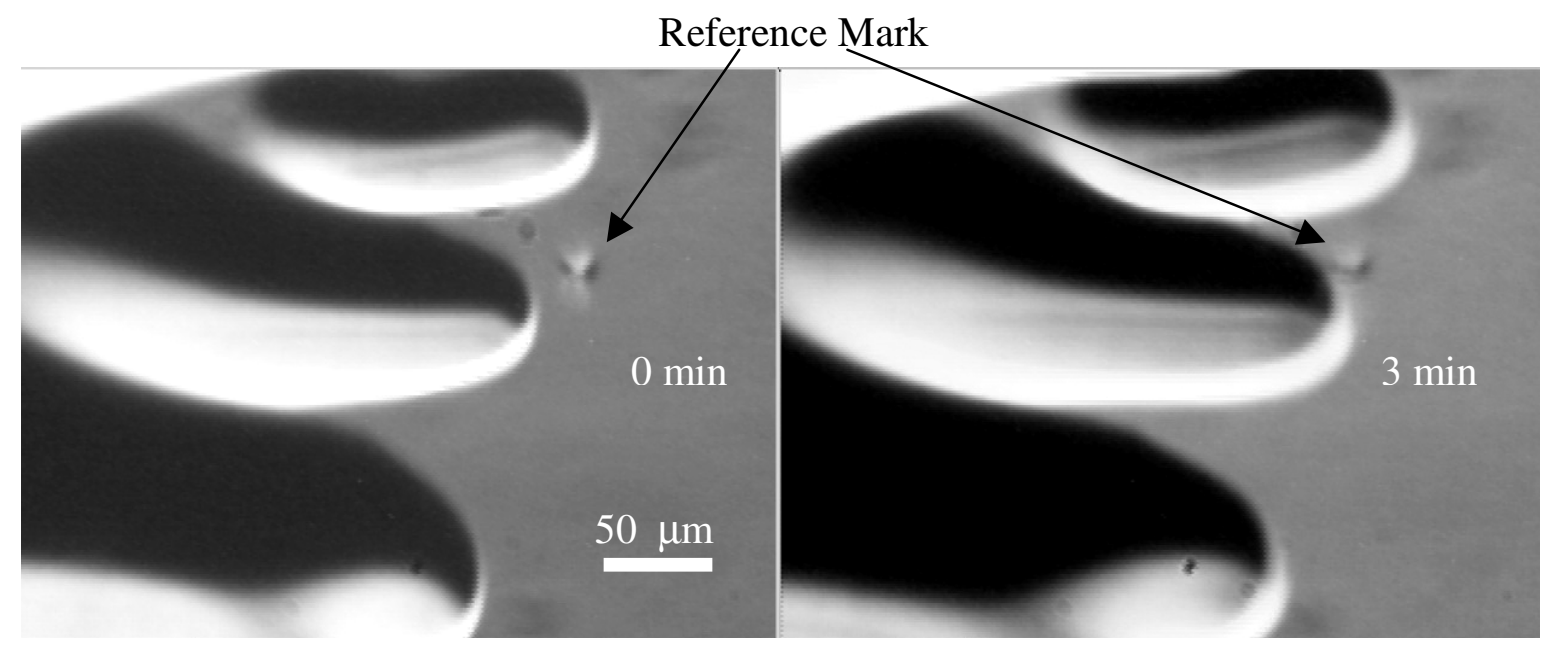

Figure 2. Water-induced blister growth.

When water is present on the edge of the sample, there is a small pressure gradient. The fluid applies a capillary force to the blister's walls, as well as the crack tip. The pressure gradient may provide extra stress at the crack tip enough to induce fracture propagation. The experimental evidence shows that the delamination continues as long as the water is present.

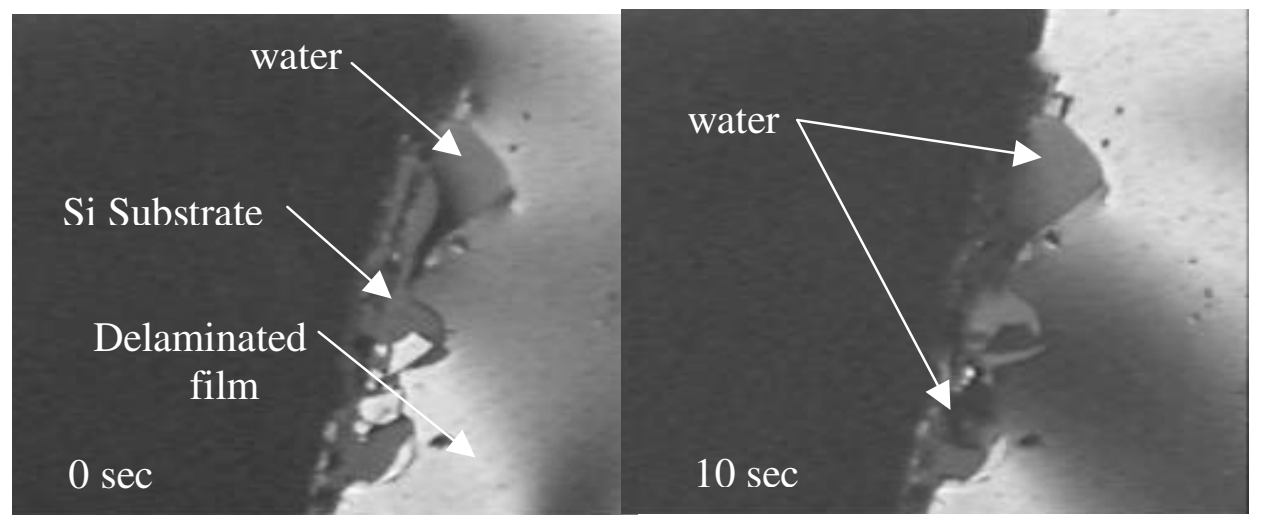

Figure 3. Water transport in the delaminated blister. 
Thin films in "dry" environment have adhesion values of over twice that in the "wet" environment. This however does not seem to be the only mechanism responsible for blisters propagation in fluids. As the value of the interfacial toughness, $\Gamma(\Psi)$, goes down, the strain energy release rate, $G$, increases due to the extra stress at the crack tip induced by the water presence. This results in the fracture criterion being satisfied:

$$
G \geq \Gamma(\Psi)
$$

Water creates a pressure gradient at the microscopic level, and also applies a capillary force to the crack tip. The subsequent change in surface tension adds the extra stress necessary to continue the blister propagation.

Following Hutchinson and Suo's analysis [13], one can estimate the steady state interfacial toughness in the direction of blister propagation for the "dry" conditions:

$$
\Gamma_{S S}=\frac{\left(1-v^{2}\right) h \sigma_{r}^{2}}{2 E}\left(1-\frac{\sigma_{B}}{\sigma_{r}}\right)^{2}
$$

as well as mode-dependent interfacial toughness in the buckling direction, perpendicular to blister propagation:

$$
\Gamma(\Psi)=\frac{\left(1-v^{2}\right) h}{2 E}\left(\sigma_{r}-\sigma_{B}\right)\left(\sigma_{r}+3 \sigma_{B}\right)
$$

Both residual $\left(\sigma_{r}\right)$ and buckling $\left(\sigma_{B}\right)$ stresses can be estimated from the geometry of the buckling profiles in Figure $1 \mathrm{~b}[7,13]$. Here, $h$ is the film thickness, and $E$ is the film elastic modulus. For the $1 \mu \mathrm{m}$ thick $\mathrm{W}$ thin film with about $2 \mathrm{GPa}$ compressive residual stress, and $275 \mathrm{MPa}$ buckling stress the steady-state interfacial toughness is $3.6 \mathrm{~J} / \mathrm{m}^{2}$, while the mode-dependent interfacial toughness is $6 \mathrm{~J} / \mathrm{m}^{2}$. These would be substantially reduced with the presence of fluid environment. Adhesion measurements using the superlayer indentation technique [14] will be performed in the future.

One can envision a microfluidic device in which the fluid transport is archived by thin film buckling delamination propagation. Delamination, thus transport direction can be guided by patterned adhesion-weakening layers, which could also allow for fluids mixing [10]. The only disadvantage of such a device would be the one-time use of its actuation mechanism. Once the stored elastic energy is relieved by buckling and blister growth, there is no driving force for further fluid flow, although the blisters would remain open for fluid transport induced by other means.

It has been previously shown that the telephone cord delamination morphology is quite stable, even when manipulated with the mechanical probe [5]. We have attempted to use a mechanical probe to transport water through the telephone cord blisters. 


\section{MECHANICALLY-INDUCED FLUID TRANSPORT}

The next stage of experiments implemented a mechanical microprobe to induce water flow through the telephone cord blister. The microprobe was attached to a rigid platform adjacent to the optical microscope stage. A titanium probe needle was used to slowly push on the blisters (Figure 4). Here, a water droplet can be seen exiting the delaminaton edge. The fact that water is present inside the blister prevents its rupture, as the film could be easily torn if too much force is applied without the water presence. The flow can also be easily reversed by changing the direction of the microprobe movement.

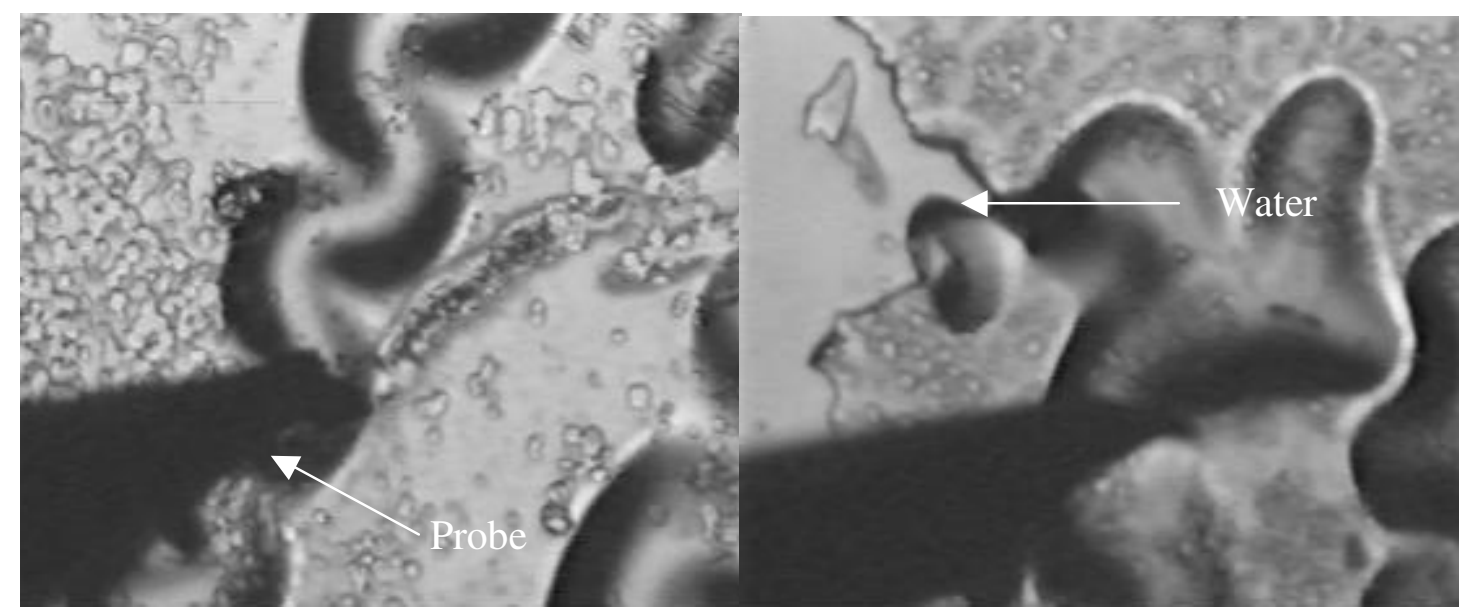

Figure 4. Mechanical microprobe manipulation.

\section{CONCLUSIONS}

Buckling delamination blisters, once static, can become an active mechanical system when fluids are introduced. These pipe-like features can be used in micro-fluidic applications for fluid transport and/or mixing.

Future studies will include the effects of fluids properties on the delamination process, as well as adhesion measurements in "wet" environment.

\section{ACKNOWLEDGEMENTS}

Authors would like to acknowledge the financial support for this research from NACE International under contract N000140210024. Superlayer deposition by D.F. Bahr's group at Washington State University is greatly appreciated. We would also like to thank Seagate Research for providing some of the samples.

\section{REFERENCES}

1. N. Nguyen, S. Wereley, Microfluidics, 1-19, 285-286, (2002).

2. A. Spence, S. Retterer, M. Isaacson, Microfabricated Model Silicon Probes with Microfluidic, Channels for Drug Delivery, NNUN Abstracts 2002/Biology \& Chemistry, p. 13, (2002). 
3. Y. Li, M.N. Gulari, K.D. Wise, Proceedings of mTAS 2003 Seventh International Conference on Micro Total Analysis Systems, October 5-9, Squaw Valley, CA USA, Vol. 2, Editors: M.A. Northrup, K.F. Jensen, D.J. Harrison, pp. 931-934, (2003).

4. A.A. Volinsky, Mat. Res. Soc. Symp. Proc. Vol. 749, W10.7, (2003).

5. A.A. Volinsky, D.C. Meyer, T. Leisegang, P. Paufler, Mat. Res. Soc. Symp. Proc. Vol. 795, U3.8, (2003).

6. World Wide Web: http://www.eng.usf.edu/ volinsky

7. A.A. Volinsky, P. Waters, J.D. Kiely, E.C. Johns, Mat. Res. Soc. Symp. Proc. Vol. 854E, U9.5, (2005).

8. V.P. Burrola, Solar Energy Materials, 117-126, (1980)

9. A.A Volinsky, N.R. Moody, W.W. Gerberich, Acta Mater., Vol. 50/3, pp.441-466, (2002).

10. M.W. Moon, K.R. Lee, K.H. Oh, J.W. Hutchinson, Acta Materialia (2004).

11. A.A. Volinsky, N.R. Moody, W.W. Gerberich, International Journal of Fracture, Vol. 119, No. 4, pp. 431-439, 2003

12. A.A. Volinsky, N.R. Moody, M.L. Kottke, W.W. Gerberich, Phil. Mag. A, Vol. 82, No. 17/18, pp. 3383-3391, 2002

13. J.W. Hutchinson, Z. Suo, Adv. In Appl. Mech., Vol. 29, pp. 63-191 (1992).

14. A.A. Volinsky, N.R. Moody, W.W. Gerberich, Acta Mater. Vol. 50/3, pp. 441-466, (2002). 